\title{
What will be the needs of Library, Museum and Archives users in the next 10 years? Research implications
}

\author{
Javier Stanziola
}

\section{Introduction}

People access and process a significant amount of information from museums, libraries and archives on a daily basis. In $2005 / 06$, more than $60 \%$ of all adults in England visited a museum, library or archive at least once (DCMS, 2007). Libraries welcomed more than 18 million adults that same year, with $60 \%$ of users visiting at least once a month. This amounted to more than 288 million visits to libraries in 2005/06. For Libraries and Museums, physical visits remain the preferred way of participation. For Archives, over 55\% of users participated by accessing web-based sites without ever visiting the actual physical site. These users are mainly interested in the core offer of these organisations: books, collections and records. It has become apparent, however, that over recent years visit levels to museums have remained constant and there has been a decline in library use. For instance, the proportion of adults visiting a museum at least once a year remains around $40 \%$. The number of library visits has dropped by close to $5 \%$ since $1997 / 1998$, with total book issues decreasing by more than $30 \%$. This signals a change in user behaviour and the need to review and improve the fit of current provision with what users require. Just as these changes affect the type and level of provision of services, they also affect the sort of research that library, museum and archives professionals need. The formulation of any future research strategy and agenda for libraries, museums and archives should be informed by and respond to emerging social, economic and political drivers and trends affecting what users expect and need from the sector.

\section{What will consumers need from Libraries, Museums and Archives in 10 years?}

No one can predict what will happen in 10 years. We can, however, inform our decision making process by developing scenarios of the future. These are extreme,

\section{Author}

Prior to joining MLA, Dr. Javier Stanziola, was a Lecturer in Economics for the Florida State University System and Head of Research and Evidence at Arts \& Business UK. He has published articles and a book on economic impact of the arts, heritage and cultural policy. In the UK, he has also worked for the New Economics Foundation and the National Endowment for Science Technology and the Arts.

\section{Email: Javier.Stanziola@mla.gov.uk}


yet plausible, stories of how key drivers of change could manifest in the future. They can help structure and guide a discussion on whether we are prepared to address these scenarios and what is a sensible strategic direction around these uncertainties ${ }^{1}$. They also help identify the potential areas of research and analysis that will be needed to help face and inform these changes. Based on research reports from the MLA Council's Research Resource Site 2 , reports on future trends from organisations such as Foresight ${ }^{3}$, data on the public domain from the Henley Centre $^{4}, \mathrm{MORI}^{5}$ and the Pew Charitable Trusts ${ }^{6}$, and national statistics and forecasts, including Social Trends (Office for National Statistics, 2008) and trended Census data, the following major ongoing and projected social and economic drivers of change have been identified (see Table 1). They are likely to have a significant effect on the expectations and needs of users and non-users and, in turn, on the type of provision offered by libraries, museums and archives in the future:

Table 1: Social and Economic Drivers of Change.

\section{Rapid Demographic Changes}

- Black and Minority Ethnic persons (BMEs) comprised 7.9\% of the population in 2001, up from $6.6 \%$ a decade earlier. Although BMEs show considerable regional concentration, trended census data show that increased segregation is not a feature of mainland Britain.

- The UK is experiencing shifting family structures, an ageing population and a rise in the number of child-free individuals.

- With rising life expectancy and falling fertility, the UK population is getting older (median age will rise from 38 in 2000 to 46 in 2050).

- The composition of the labour market has changed significantly in the past 30 years. In $1971,56 \%$ of women were employed. In 2005, this proportion was closer to $70 \%$. $79 \%$ of males were employed in 2006 , down from $92 \%$ in 1971.

- These trends are likely to be altered by the rapid increase in immigration experienced in the past decade.

\section{Changing nature of community}

- As a consequence of increased mobility and the growth of individualism in society, community and identity are no longer simply based on geography.

- There are clear regional differences in people's sense of belonging to where they live: $36 \%$ in London feel that there is a sense of community; compared to $62 \%$ in Wales.

\footnotetext{
${ }^{1}$ See Foresight (http://www.foresight.gov.uk/)

2 http://research.mla.gov

3 http://www.foresight.gov.uk/

4 http://www.henleycentre.com

5 http://www.ipsos-mori.com

6 http://www.pewtrusts.com
} 
- Interests outside of one's local area have an important influence on the changing nature of community in Britain.

- There is a growing association with the global community amongst higher income groups as well as individuals maintaining multiple communities -here and abroad.

- Research shows that few people identify emotionally with Britishness and that regional identities are still important for many.

- Other kinds of identities are more important to people's everyday lives: e.g. ethnic identities are prominent.

\section{Growth of virtual/online communities and changing nature of ICT}

- Individuals with access to media technologies are increasingly able to create their own media content and are establishing membership in virtual communities at a fast pace (e.g. a blog is created every 3 seconds; Vlogs are also rapidly growing in popularity.)

- Whereas once people were dependent on the information broadcast by official channels, we can now access the views and experiences of ordinary people.

- For some, belonging to these virtual communities has eclipsed the significance of face-to-face contact in every day life.

- As social networking (e.g. MySpace) becomes the norm, a tightly related but unique in its consequences Web 3.0 generation will emerge. This generation will rely on collective intelligence (e.g. Wikipedia) and will perceive academics, media and other authorities differently. Decisions will be made based on the systematic creation of data and results that received the highest "ranks".

- Internet advertising has overtaken press advertising in some countries. Research suggests the broadcasting industry will experience significant changes in the next 10 years, with the likely outcome of a more decentralised sector with many more consumers who are experts on "broadcasting" messages.

\section{Shifting sense of responsibility from community to self}

- The majority of consumers now believe that taking care of oneself is the best route to raising standards for everyone. This is particularly the case for the low to mid range of socio-economic groups.

- The number believing that the government should redistribute income from the better off to the less well off is also gradually declining: $45 \%$ agreed they should in 2005 compared to $49 \%$ in 2000 .

- There is a rising public demand for corporations to play a wider role beyond maximising investor return. This is in part a response to the growth in influence of big business, and the consequent power it holds.

- Companies are responding with a wealth of Corporate Social Responsibility 
(CSR) initiatives. Almost all major companies now produce an annual CSR report detailing their commitments.

- Some companies are responding by taking on former state concerns.

- The rise of venture philanthropy is seen as the natural next step of the CSR movement.

- Many indicators point to perceptions of declines in "deference". This includes rising antisocial behaviour.

- $78 \%$ of people in the UK in 2004 agreed that young people don't respect traditional values, up from 63\% in 1997.

\section{Increased awareness of natural resource constraints}

- We are experiencing increased energy demand from rapidly developing economies such as China, India and Brazil. But no major oils fields have been found since 1976.

- By 2025 , up to $40 \%$ of the world's population could live in water scarce regions.

- Natural resources constraints are likely to exacerbate socioeconomic inequalities in the UK (and abroad).

- There is potential for increasing numbers of environmental refugees.

- There is an increased awareness that something needs to be done about "Climate Change" as long as it is easy to do and everyone else is doing it too.

\section{Higher Demand for Informal Education Opportunities}

- For increasing numbers of the population, education is no longer confined to compulsory schooling. Early learning and participation in pre-school education is seen as important for building a foundation for future learning, and most people continue in full-time education beyond school-leaving age.

- Qualifications attained at school are increasingly supplemented by further and higher education and other training, to equip people with the skills required by a modern labour market, and to keep these skills up to date.

\section{Growth of Consumption Culture and Empowered Consumers}

- Total consumer debt has more than doubled since 1996 and is now more than $£ 1.1$ trillion.

- There are signs, however, that this is starting to grow more slowly. According to the Bank of England, consumer debt grew at its slowest rate since 1994 in December 2005.

- This consumption culture helps some individuals express their personal identities and articulate beliefs about the national economy, social and environmental issues and civic life.

- Individuals have increasingly high expectations of the organisations and 
businesses that they deal with.

- They have a wealth of information at their fingertips and can rapidly compare offers and prices.

- Levels of complaints about companies that are perceived to be providing a poor service have stabilised in recent years: however, growing numbers of consumers are using the power of exit to express their discontent. 35\% also claimed to have told friends and relatives to stop buying from a particular company in 2005.

- Coupled with the government choice agenda, this trend means that citizens will increasingly be able to shop around for the best public sector provision.

\section{Mixed UK Economic Performance}

- The economy is expected to keep on growing but at a significantly much slower rate, with changes to financial regulation.

- It is widely expected that public spending will grow at a slower rate than it did in the past 5 years.

- The issue of a 'north-south divide' looks set to persist within the UK. Underlying trends towards economic inequality will probably continue, and will continue to have some knock-on impact on other services, e.g. education, although spending allocations may try to reduce these.

- Income inequalities in the UK are high when compared to other wealthy nations or to previous decades.

- The UN reports that child poverty in the UK has fallen. But, the UK has one of the highest rates of child poverty in the rich world, with more than $15 \%$ of families with children living on less than half the UK average income.

- Wealth inequality continues to widen. In $2004 / 05$, almost $2 / 3$ of the population had incomes below the equivalised national average of $£ 427$.

\section{How are libraries, museums and archives likely to respond to these drivers to ensure their sustainability?}

Here are 4 plausible scenarios:

\section{SCENARIO 1: Libraries, museums and archives will offer more customized and "exciting" entertainment events to attract visits to their "core offer". Edutainment, so despised by many, is here to stay. The blockbuster exhibitions and "theme-park" approach to exhibitions, currently limited to Super Star Museums, will become the norm for most regional and local organisations. As young people - raised with the likes of the always-evolving MySpace.com and interactive video games and TV - become young adults and professionals, the demand for information services as they are being offered today will decrease significantly. To ensure their survival and still meet their core goals, libraries, museums and archives will increase significantly the offer of customized and}


“exciting" entertainment events and opportunities to socialize with peers and family.

SCENARIO 2: Libraries, museums and archives become key providers of informal and personalised education opportunities in England. Taking advantage of their infrastructure and resources (e.g., online data, staff, artefacts, trusted social spaces) and the continued growth in demand for informal education, libraries and museums will gain a reputation for providing a wide variety of meaningful, informal - yet structured - learning opportunities for adults and children.

\section{SCENARIO 3: Work currently labelled as "Social Inclusion", "Outreach" and "Identity-building" by most libraries, museums and archives becomes integrated into their main marketing and public relations functions. As the proportion of migrants, and older $(75+)$, non-White and non-Christian consumers increases, their needs and wants will no longer be labelled as "fringe" and become "mainstream". This means that anticipating, identifying and satisfying their particular social and identity needs will become a necessity for most libraries, museums and archives to remain relevant and to ensure their financial survival. Community Engagement, far from being a disjointed service, will become integrated into other marketing and public relations functions to support the development and implementation of new services.}

SCENARIO 4: Libraries, museums and archives will operate using different business models and will increasingly rely on a diversified sustainable portfolio of funding sources. As views on the role of government, business and the community start to change, the government will encourage consumers and businesses to collaborate with libraries, museums and archives in implementing new business models and to support them more proactively in the form of joint or community partnerships, donations, tickets, venture philanthropy and sponsorship. This will also mean that the ownership and management of services and staff in museums will be significantly altered to replicate commercial, for-profit models even more astutely.

\section{Research Implications}

These future scenarios suggest that any research agenda to support the delivery of library, museums and archive services should concentrate on applying existing research to development of new services and applying existing methodologies to capture the outcomes and impact of libraries, museums and archives:

- Research and Development: What works in informal learning? How to respond to the shifting needs of users? How to attract non users? How can we use new technology not only to promote our existing core offer but also to provide access and help process information? There is an extensive and authoritative body of research providing theoretical frameworks, testing models and identifying what works (and doesn't) in all these areas. We should avoid the tendency to commission or undertake further research on these areas so they apply to a particular circumstance or to make it more sector-specific. Scarce resources should be invested instead in synthesizing existing work to distil and - crucially - apply its policy and programme 
implications to support service innovation. Research on these topics should stop being perceived as "for information" by decision makers, and start playing its rightful role as the engine of service and product "development".

- Applying existing methodologies: The effects of libraries, museums and archives services on users are evident to sector professionals. After decades of trying to communicate these outcomes to policy makers and practitioners in other fields, the perception of libraries, museums and archives having a limited impact on social and economic outcomes persists. To remedy this, some academics call for the development of new models and methodologies that wholly capture the full value of these services. Before embarking on such development, it is worth reviewing the vast literature on the subject that has been written in the past 2,000 years (Belfiore, 2006). This body of work suggests that infallible all-inclusive models cannot be developed and that an interdisciplinary approach to apply existing models and methodologies is the most sensible way forward. For example, Social Return on Investment's framework and methods, whilst limited in many ways, provide a powerful tool to demonstrate value to businesses and public bodies and support innovation. Theories of Change approaches provide a good framework to conceptualise how to develop community engagement activities that are outcomes-focused.

\section{References}

Belfiore, E. (2006) The unacknowledged legacy: Plato, The Republic and cultural policy. International Journal of Cultural Policy, Special Issue: Intellectuals and Cultural Policy, 12(2).

Department for Culture, Media and Sport (2007) Taking Part: the National Survey of Culture, Leisure and Sport, Annual Report 2005-6. URL:

http://www.culture.gov.uk/Reference library/Publications/archive_2007/tps annu alreport0506.htm [accessed 24.04.08].

Office for National Statistics (2008) Social Trends, 38. URL:

http://www.statistics.gov.uk/StatBase/Product.asp?vlnk=5748 [accessed 24.04.08] 